\title{
WIND TURBINE SIMULATION AND CONTROL USING SQUIRREL-CAGE INDUCTION GENERATOR FOR DFIG WIND ENERGY CONVERSION SYSTEMS
}

\author{
Ahmed G. Abo-Khalil ${ }^{\mathrm{a}, \mathrm{b}}$ and Khairy Sayed $\mathrm{d}^{\mathrm{c}^{*}}$ \\ ${ }^{a}$ Department of Electrical Engineering, College of Engineering, Majmaah University, Almajmaah 11952, Saudi Arabia \\ ${ }^{b}$ Department of Electrical Engineering, College of Engineering, Assuit University, Assuit 71515, Egypt \\ ${ }^{c}$ Electrical Engineering Department, Sohag University, 82524, Sohag, Egypt
}

\begin{abstract}
This work presents the design and implementation of a wind turbine simulator to carry out laboratory tests on the generation, regulation, and control of a wind power conversion system (WECS) with a capacity of $3 \mathrm{~kW}$. A three-phase squirrel-cage induction motor emulates the static and dynamic wind turbine characteristics based on the torque-speed profile of a wind turbine. The Emulator allows all electromechanical tests to be carried out, from the characterization of the generator to the adjustment of controls and protections for equipment operating in a specific location. Initial Emulator tests were successful.
\end{abstract}

(C) 2021 Published by Faculty of Engineering - Sohag University. DOI: 10.21608/SEJ.2021.155556

Keywords: DFIG; wind shear; wind turbine simulator.

\section{INTRODUCTION}

Globally, electricity generation based on wind energy is currently one of the most widely used and fastest growing renewable energy sources, with the expectation that by 2020 it will account for $12 \%$ of total energy demand worldwide [1]. On a small scale, in facilities of less than $10 \mathrm{~kW}$, there is an active market aimed mainly at private users [2] in isolated locations or who wish to take advantage of the subsidies offered by various state institutions.

Most of these installations have been carried out or are being planned in developed countries, the only ones that currently can afford the large investments necessary to install and develop equipment that already reach 5MW per turbine.

Given the existing interest in low-power wind systems, it is necessary to develop a system that allows this equipment to be subjected to laboratory tests, both to evaluate the new designs of the research groups and to standardize the existing equipment on the market, perform quality control and serve as training tools for personnel dedicated to providing service to installed systems. The tests of the electric wind turbine must cover two parts, each with different requirements:

\footnotetext{
* Corresponding author. E-mail address: khairy_sayed@eng.sohag.edu.eg
} 
1- Aerodynamic tests of the wind turbine either at scale or in real size.

2- The tests of the other electromechanical and electronic equipment that make up the electric wind turbine, for which it is necessary to connect said equipment to an axis that emulates the torque / speed characteristics of the wind turbine.

In general, the turbine emulators reported in the literature are based on the model of the turbine to be emulated, specifically, in relation to its angular power / torque curves, which defines the torque reference that the motor wants to reproduce. .

Regarding electrical machines, the use of DC and AC machines has been proposed. In [3], a DC motor is used to which a series resistor is connected in the armature; the solution is simple, however, the energy losses in the series resistance are very high. In other cases as [4], a speed control is used for the motor, whose reference is obtained from the turbine model to be emulated; Although the solution seems attractive, however, the results seem not to be convincing. With a very similar torque control scheme, an emulator that only reproduces the maximum power points of the turbine is proposed in [5].

In addition, there are some other variants, such as [6], where a torque sensor is used in order to improve the correspondence between the torque at the motor output and the torque of the turbine. Another important aspect of the behavior of a turbine is its inertia, which is poorly addressed in previous articles.

Inertia is linked to turbine dynamics and defines the response time between one operating point and another, which is important e.g., in the design of WECS control systems. Since the inertia of an electric motor as an emulator is not equal to the inertia of a real turbine, then it is necessary that an inertia compensation component be included in the emulator.

In this sense, emulators based on AC machines do usually include inertia compensation. In the case of [7], [8], and [9] use is made of a Permanent Magnet Synchronous Machine and a torque control; the steady state experimental results guarantee the correct functioning of the system, however, it is highlighted that in [7] and [8] inertia is not included; while [9] addresses inertia compensation and illustrates its dynamics in the face of torque changes, and it also contemplates tower shadow and wind shear phenomena (differences in wind speed due to tower and to the vanes position). Other proposals of emulators make use of the Squirrel Cage Induction Machine (SCIM), as is the case of [10] and [11]; in the case of [11], among other things, it addresses various types of turbine and does consider inertia compensation. Steady state results are good, but no transient analysis associated with inertia compensation is shown.

In relation to previous reviews, this work proposes the design of a wind turbine emulator based on a SCIM and a Back-to-Back converter that does contemplate inertia compensation. Specifically, SCIM control is done using torque control and magnetic flux based on vector control.

The document is organized as follows: Section 2 provides the static/dynamic modeling of a wind turbine and its dimensioning; Section 3 describes the components of the turbine emulator and deals with the modeling of some emulator components for the design of the emulator control system; Section 4 shows the experimental results obtained from the implementation of the emulator. Finally, Section 6 provides the conclusions of the work.

\section{Mathematical Model of Wind Turbine Emulator}

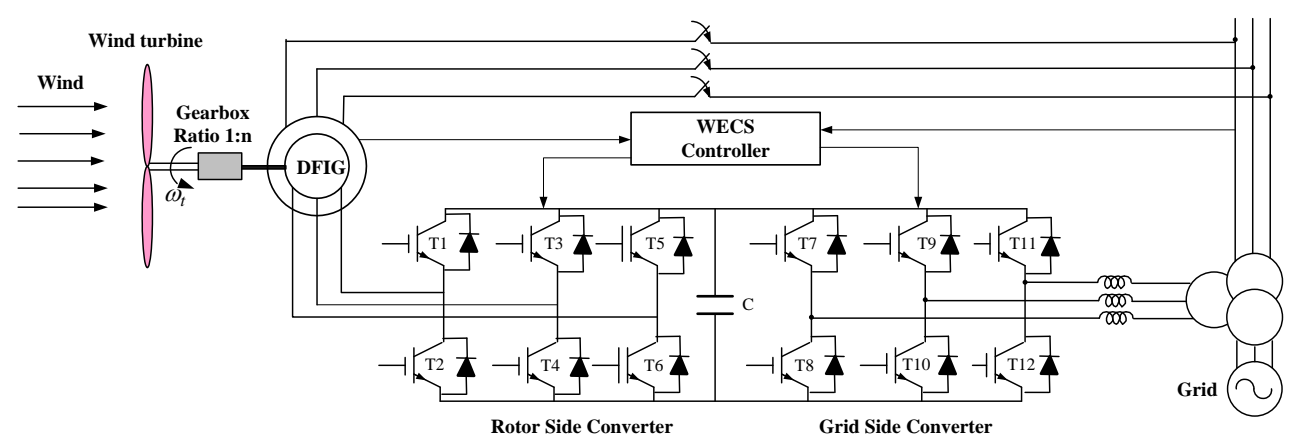

Fig 1. Wind turbine emulator. 
Understanding the wind dynamics in wind turbines is of great importance, since these have a higher efficiency given by the restrictions imposed by the Betz limit [12]; that is, no three-bladed cross-section wind turbine has an efficiency greater than the maximum possible efficiency according to the curve of the power coefficient (0.593), that is, how much of the effective wind power can be transferred to mechanical power in the turbine rotor; This restriction is physically explained in [13]. After multiple tests with rotors connected to three-blade turbines and a sweep of wind speeds, the graphs of the power coefficient versus blade tip speed at different angles of â are obtained, as shown in Fig. 1.

\subsection{Wind Turbine Model}

Likewise, the general model of the turbine rotor (Equation 1) was taken from [13], in which the equation of the power coefficient is presented (Equation 2), this being a relationship between wind power and mechanical power which gets transferred to the turbine rotor. Equation (2) applies to all three bladed turbines where parameters $\mathrm{C}_{1}, \mathrm{C}_{2}, \mathrm{C}_{3}, \mathrm{C}_{4}, \mathrm{C}_{5}, \mathrm{C}_{6}$ were found by means of a regression algorithm. Also, in Equation (2) $\beta$ is the angle of attack of the cross section of the blades with respect to the wind direction; in small-scale turbines this value is fixed and is usually close to zero since, according to Fig. 2, this is the angle at which the turbine achieves the highest efficiency. $\lambda_{i}$ is a relation represented in Equation 3 and $\lambda$ is the blade tip speed of the turbine that depends proportionally on the radius of the blades in $\mathrm{m} . \omega$ is the angular speed of the turbine rotor with units in $\mathrm{rad} / \mathrm{s}$, and inversely proportional to the speed of the wind speed in $\mathrm{m} / \mathrm{s}$ as seen in Equation 3: [18], [19]:

$$
\begin{aligned}
& P_{t}=\frac{1}{2} \rho \pi R^{2} v^{3} C_{p}(\beta, \lambda) \\
& C_{p}(\beta, \lambda)=C_{1}\left(\frac{C_{2}}{\lambda_{1}}-C_{3} \beta-C_{4}\right) e^{\frac{-C_{5}}{\lambda_{1}}}+C_{6} \lambda \\
& \frac{1}{\lambda_{1}}=\frac{1}{\lambda-0.089 \beta}-\frac{0.035}{\beta^{3}+1}
\end{aligned}
$$

where $\rho$ is the standard air specific density $\left[\mathrm{kg} / \mathrm{m}^{3}\right], C_{p}$ is the power conversion coefficient, $\beta$ is pitch angle of turbine blades [degree], $v$ is the wind speed [m/s], $\lambda$ is the tip-speed ratio (TSR), and R is the blade radius [m].

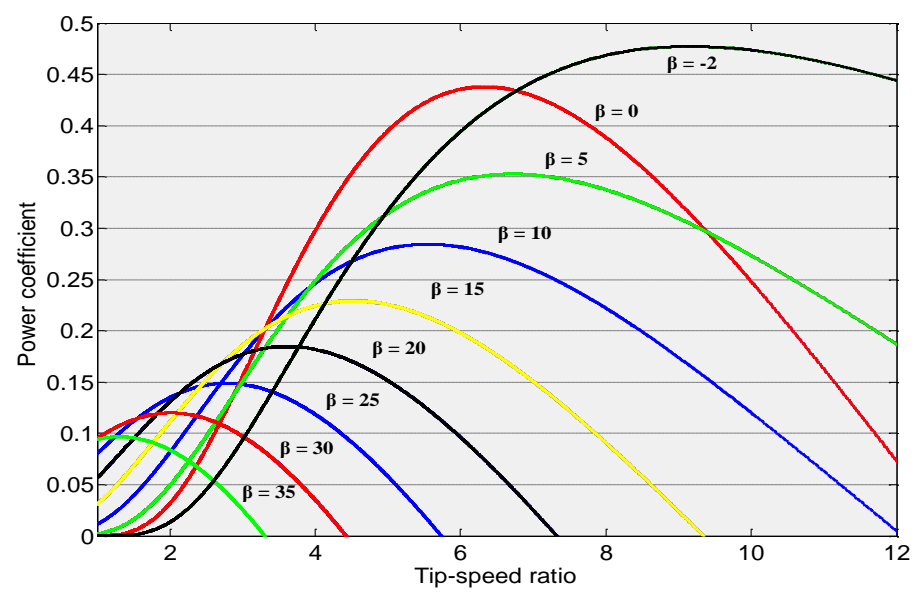

Fig. 2. Variation of power conversion coefficient with pitch angle $\beta$.

A regression process can be applied in Matlab to find the values of the specific parameters of the curve, which are $\mathrm{C}_{1}=4.152 ; \mathrm{C}_{2}=4 ; \mathrm{C}_{3}=0.06959 ; \mathrm{C}_{4}=1.616 ; \mathrm{C}_{5}=3.34 ; \mathrm{C}_{6}=0.01886$. Taking into account that $\beta=0$, since it is a low power turbine with a fixed rotor in which its angle does not vary; the model includes $\beta$ because it applies to any three bladed transverse turbine, regardless of size [20]. 
To calculate the blade tip speed $\lambda$, use is made of the expression given in [21] as presented in Equation 4, where $\omega_{t}$ is the angular speed of the rotor in $(\mathrm{rad} / \mathrm{s})[22]$ :

$\lambda=\frac{\omega_{t} R}{v}$

The electrical output power of a wind turbine depends on the wind speed and each turbine has a specific power curve [23]. Wind turbines work in different operating regions, which define the appropriate control structure, based on aerodynamic characteristics and wind speed [24], as shown in Fig. 3.

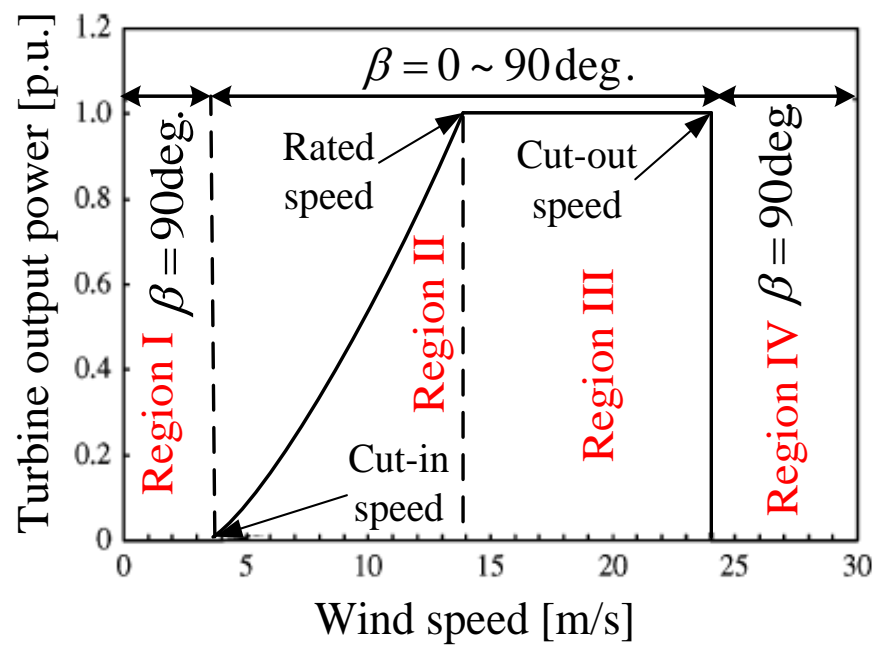

Fig. 3. Power curve in different modes

The four most important regions of operation are explained below [25]:

1. Region I. It occurs when the wind speed is less than the connection speed. In the case of Fig. 3 (a), it is located to the left of $4 \mathrm{~m} / \mathrm{s}$, a region that is defined by the minimum operating losses of the system. It includes the time in which the turbine is not in operation until it is about to start delivering power [26].

2. Region II. In this region, the power extracted from the turbine depends on the relationship between the speed of rotation and that of the wind. In the case of Fig. 3 (a), it is between 4 and $13 \mathrm{~m} / \mathrm{s}$ wind speed. Aerodynamic losses prevent the turbine from drawing maximum theoretical wind power. These losses give rise to the so-called Betz limit. In this region, the control system defines the operating point, which is given by the maximum power monitoring algorithm [27].

3. Region III. This region occurs when the nominal design power is reached, for example, when the wind speed produces a power that exceeds the nominal electrical power of the generator. In Fig. 3 (a), it is the region between 13 and $25 \mathrm{~m} / \mathrm{s}$. The turbine must limit existing power, so that it does not exceed the maximum design power. In this region of operation, the maximum power point search algorithm is usually modified in such a way that the extracted power is nominal [28].

4. Region IV. This region occurs for high wind speeds, in the case of Fig. 3(a), for wind speeds greater than $25 \mathrm{~m} / \mathrm{s}$. When the nominal power of the machine is managed and the rotation speed is exceeded, it is necessary to interrupt the rotation of the machine to preserve its integrity, which causes a stop in the generation of energy. Generally, this occurs under extreme environmental conditions [29].

\subsection{Pitch Angle Control}

A factor of great importance in the design of wind systems is the configuration of these in terms of power regulation. Wind turbines are designed and controlled with the aim of operating at their rated power for the longest possible time. It is true that the power regulation mechanisms have the objective of limiting the speed of 
the turbine to values greater than the rated speed of operation, and thus avoiding the excessive mechanical efforts caused in the turbine at such speeds. Under this perspective, the presence of a control system in a wind generation is of great value and has the purpose of safe operation, tracking of maximum power and greater efficiency of the generation system. Thus, the main state parameters that can be controlled in a wind turbine are generator electromechanical torque, turbine torque, pitch angle, brake system torque, active and reactive power flow, power factor and terminal voltage of the generator. The study of these parameters can be further investigated in [30] [32]. In this section, three ways of controlling the power produced by the turbine will be presented.

According to this type of control, the speed and power produced by the turbine can be controlled by means of an active control that allows the adjustment of the pitch angle. A mechanical device is responsible for rotating the blades longitudinally, that is, the increase of the pitch angle is obtained by rotating the front cross section of the blade that is in the direction of the incident wind towards the rotation plane, and in this way, acting reducing the portion of the blade. lift force in the direction of movement. The effect of the pitch angle variation is the reduction of the net force in the direction of movement and consequently there is a decrease in the power produced by the turbine. In the operation situation of the turbine with lower than nominal winds, the pitch angle will be fixed at a value close to $0^{\circ}$. With the increase in wind speed exceeding its nominal value, the power generated is kept constant through the step angle adjustment [33]. The increase in pitch angle is responsible for a proportional decrease in torque and mechanical power in wind turbines. This type of control has the advantage of the mechanical efforts produced by the rotor on the structure of the wind turbine being less than in turbines with stall control. In this way, the structural design of the tower and wind turbine structures requires a smaller mechanical structure, and this results in the reduction of its total weight. In addition, the control of the pitch angle has the advantage, in the case of an emergency stop of the turbine, smoother response when compared to stopping the turbine using the brake torque [34-37]. This control is also used for the simple start of a wind turbine. In [38] it is shown the departure and the shutdown of a turbine using the pitch control. The pitch angle controller consists of the speed and power controllers, of which block diagram is shown in Fig. 4.

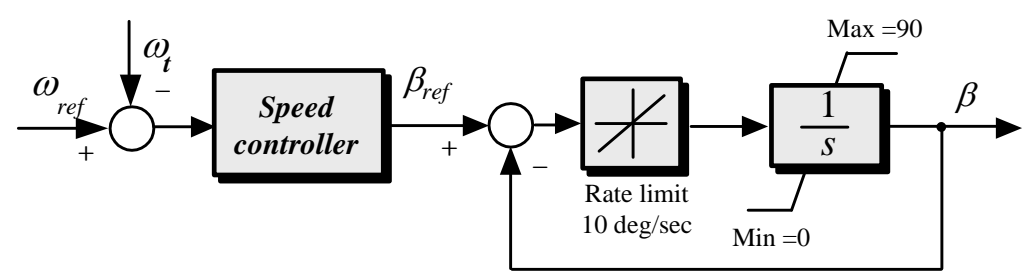

Fig. 4. Pitch angle controller

\subsection{Dynamic Model and Inertia Compensation}

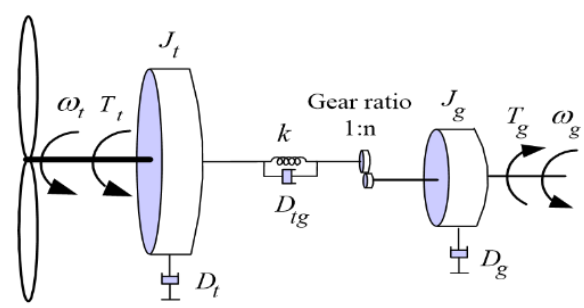

(a)

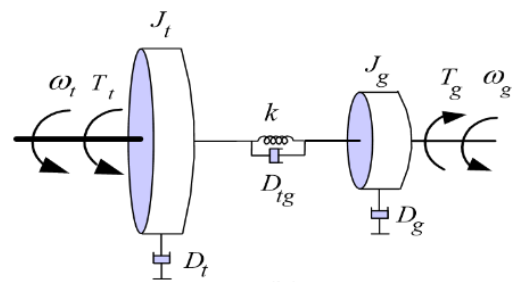

(b)

Fig. 5. (a) WECS mechanical subsystem. (b) Mechanical turbine subsystem reflected to the high-speed side.

The mechanical subsystem of the wind turbine is described in Fig. 5(a); where is the $J_{t}$ inertia of the turbine; $T_{g}, \omega_{g}, J_{g}$ are the torque, speed and inertia of the generator, $k$-Stiffness of coupling shaft; $D$ - Coupling shaft damping, and $n$ is the gearbox transmission ratio. Since the emulator will be coupled directly 
to the generator, the variables and parameters of the turbine are transformed to the high-speed side, this transformation is shown in Fig. 5(b). Values are given by: $\omega_{h}=n \omega_{T}, T_{h}=T_{t} / n, J_{h}=J_{t} / n^{2}$ [39]-[42].

The inertia of the motor $\left(J_{M}\right)$ is not equal to that of the turbine, so it is necessary to make an inertia compensation. This work proposes to compensate the inertia together with the torque control of the motor, which is an option at no extra cost and adjustable to the inertia value of any turbine that you want to emulate, which does not happen when compensating inertia e.g. by means of flywheels.

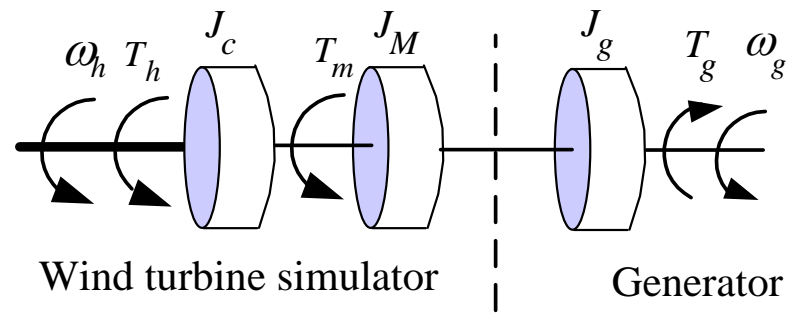

Fig. 6. Model of the mechanical emulator system with inertia compensation.

In the proposed inertia compensation mechanism, the compensation inertia $\left(J_{c}\right)$ should be added to the motor's own inertia $\left(J_{M}\right)$, see Fig. 6 . In this sense, the value of the compensation inertia should be: $J_{c}=J_{h^{-}} J_{M}$.

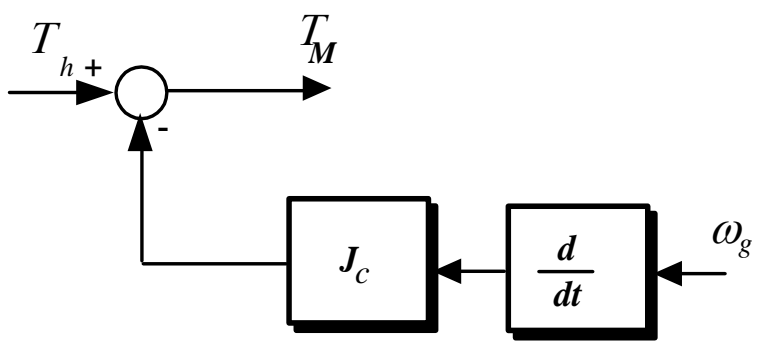

Inertia compenseation

Fig. 7. Torque reference with inertia compensation for torque control of the SCIM.

According to Fig. 7, the mathematical model between $T_{h}$ and $T_{M}$ (motor torque) is [43]:

$T_{M}=T_{h}-J_{c} d \omega_{t} / d t$

From which a $T_{M}^{*}$ reference can be defined as indicated in (4) or in Fig. 5:

$T_{M}^{*}=T_{h}^{*}-J_{c} d \omega_{t} / d t$

Torque reference $T_{h}^{*}$, includes torque reference $T_{M}^{*}$ provided by the static model of the turbine, equation (1); and the dynamics associated with inertia compensation; that is $T_{h}^{*}$, it is a slowed down version of $T_{M}^{*}$. With this, it is possible to propose a torque control loop $\left(T_{M}\right)$ of the SCIM, whose reference is given by (6).

For any wind speed value, the turbine torque can be expressed as [44]:

$T_{t}=0.5 \rho R^{3} C_{t}(\lambda, \beta) v^{2}$

\section{Induction Motor Control}

The control of the motor side is based on the SCIM dq model given by the following equations [45] 


$$
\begin{aligned}
& v_{d s}=i_{d s} R_{s}-\omega_{e} \lambda_{q s}+p \lambda_{d s} \\
& v_{q s}=i_{q s} R_{s}+\omega_{e} \lambda_{d s}+p \lambda_{q s} \\
& 0=i_{d r} R_{r}+\left(\omega_{e}-\omega_{r}\right) \lambda_{q r}+p \lambda_{d r} \\
& 0=i_{q r} R_{r}+\left(\omega_{e}-\omega_{r}\right) \lambda_{d r}+p \lambda_{q r} \\
& T_{e}=\frac{3}{2} \frac{P}{2} \lambda_{d r} i_{q s}=K i_{d s} i_{q s}=K_{t} i_{q s} .
\end{aligned}
$$

where $v_{d s}$ and $v_{q s}$ are the stator voltages, $i_{d s}$ and $i_{q s}$ are the stator currents, $\omega_{e}$ is the reference frame speed, $\omega_{r}$ is the rotor speed, $\lambda_{d s}$ and $\lambda_{q s}$ are the stator flux linkages, $\lambda_{d r}$ and $\lambda_{q r}$ are the stator flux linkages, $T_{e}$ is the electromagnetic torque, and $P$ is the number of poles [46].

Regarding the external loop for torque control (relationship between $T_{e}$ and $i_{q S}$ ), only one reference is defined in terms of $T_{e}$. Thus, controlling $i_{q s}$ guarantees a continuous variable torque as shown in (12). In experiment, the wind speed pattern and turbine reference torque are implemented by (7). The torque current reference $i_{q s}^{*}$ is then calculated from the torque equation by dividing it by the torque constant $K_{t}$ in (12), as shown in Fig. 8 [47].

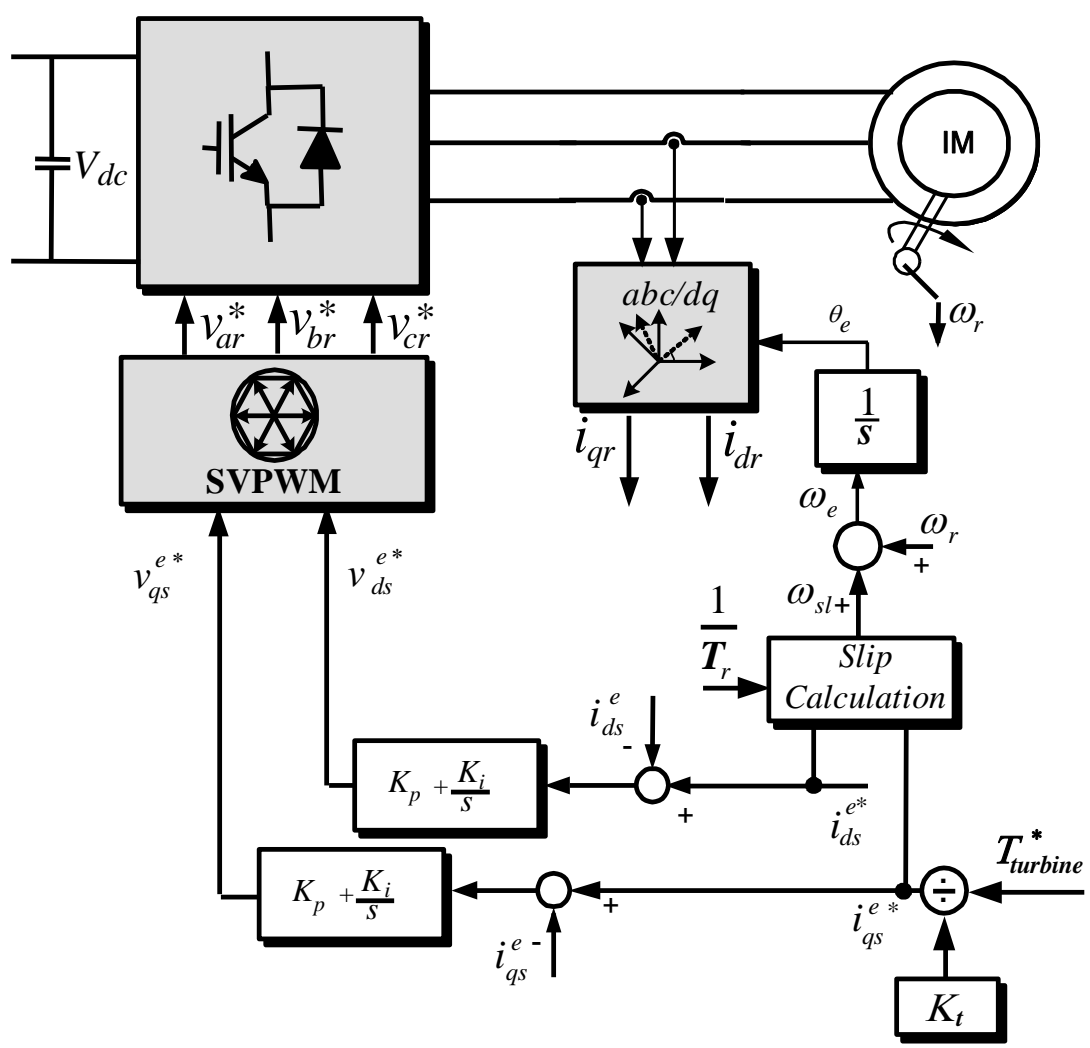

Fig. 8. Block diagram for controlling the induction motor.

In fact, the motor reference $d$-axis current is kept constant at the value that maintains the minimum iron loss. The GSC is controlled by means of an internal current control loop and an external DC bus regulation loop.

The grid-side converter (GSC) is controlled by and external DC-link voltage control loop which keep the DClink voltage constant, and the output power factor is set to unity by using two internal control loop to control the grid-side $q$-axis current and the $d$-axis current. Fig. 9 depicts the control block diagram of the grid-side converter. 


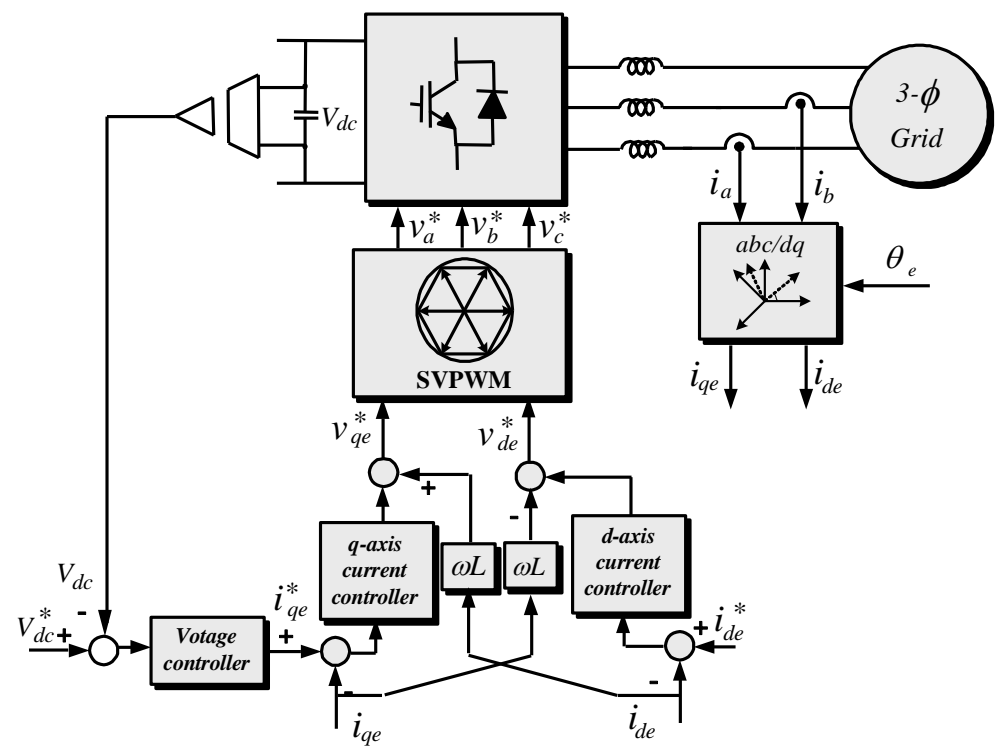

Fig. 9. Control block diagram of grid-side converter.

\subsection{DFIG Control}

To control the active and reactive power in the stator side, a d-q reference frame synchronization with the stator flux is selected. The flux vector in the stator is aligned with the $d$-axis. The flux linkage of the rotor and stator is defined as [48]

$$
\begin{aligned}
& \lambda_{s}=\lambda_{d s}=L_{m} i_{m s}=L_{s} i_{d s}+L_{m} i_{d r} \\
& \lambda_{d r}=\frac{L_{m}^{2}}{L_{s}} i_{m s}+\sigma L_{r} i_{d r} \\
& \lambda_{q r}=\sigma L_{r} i_{d r} \\
& \sigma=1-\frac{L_{m}^{2}}{L_{r} L_{s}}
\end{aligned}
$$

where $L_{m}$ is the equivalent magnetizing inductance, $L_{s}$ is the equivalent stator self-inductance, $L_{r}$ is the equivalent rotor self-inductance, $\lambda_{d s}, \lambda_{q s}$ are the equivalent $\mathrm{d}$-q flux linkage in the stator, $\lambda_{d r}, \lambda_{q r}$ are the equivalent rotor d-q flux linkage, and $i_{m s}, i_{d s}, i_{d r}$ are the magnetizing d-axis currents in the stator and rotor.

Rotor voltages in the d-q reference frame can be written in terms of rotor and stator magnetizing currents [49]:

$v_{d r}=R_{r} i_{d r}+\sigma L_{r} \frac{d i_{d r}}{d t}-\omega_{s l} \sigma L_{r} i_{q r}$

$v_{q r}=R_{r} i_{q r}+\sigma L_{r} \frac{d i_{q r}}{d t}+\omega_{s l}\left(\sigma L_{r} i_{d r}+\frac{L_{m}^{2}}{L_{s}} i_{m s}\right)$

where $v_{d r}, v_{q r}$ are the d-q voltages in the rotor, $R_{r}$ is the rotor equivalent resistance, and $\omega_{s l}$ is the slip angular frequency. The stator flux angle is expressed as

$\lambda_{d s}^{s}=\int\left(v_{d s}^{s}-R_{s} i_{d s}^{s}\right) d t$ 
$\lambda_{q s}^{s}=\int\left(v_{q s}^{s}-R_{s} i_{q s}^{s}\right) d t$

$\theta_{e}=\tan ^{-1} \frac{\lambda_{q s}^{s}}{\lambda_{d s}^{s}}$

where the superscript $s$ represents the parameters in the stationary reference frame, $R_{S}$ represents the stator resistance, and $\theta_{e}$ represents the synchronous frame angle. Regulating the $q$-axis component of the rotor current controls either the active power of the DFIG stator side or the developed torque in the generator.

$$
P_{s}=\frac{3}{2}\left(v_{q s} i_{q s}+v_{d s} i_{d s}\right)=-\frac{3}{2} \cdot \frac{L_{m}}{L_{s}} \cdot v_{q s} i_{q r}
$$

To directly control the stator-side reactive power, the rotor $d$-axis current component should be regulated. This reactive power can be expressed as

$$
Q_{s}=\frac{3}{2}\left(v_{q s} i_{d s}-v_{d s} i_{q s}\right)=\frac{3}{2} \cdot \frac{L_{m}}{L_{s}} \cdot v_{q s}\left(i_{m s}-i_{d r}\right)
$$

The stator active and reactive powers are proportional to the current components $i_{q r}$, and $i_{d r}$, respectively. The DFIG wind turbine system configuration consists of a DFIG connected to the utility grid through its stator. The back-to-back PWM power converters enable a bidirectional power-flow control. As a result, the DFIG can operate either in sub-synchronous $\left(\omega_{r}<\omega_{e}\right)$ or in super-synchronous modes $\left(\omega_{r}>\omega_{e}\right)$. The schematic diagram of the simplified control scheme is shown in Fig. 10 [50].

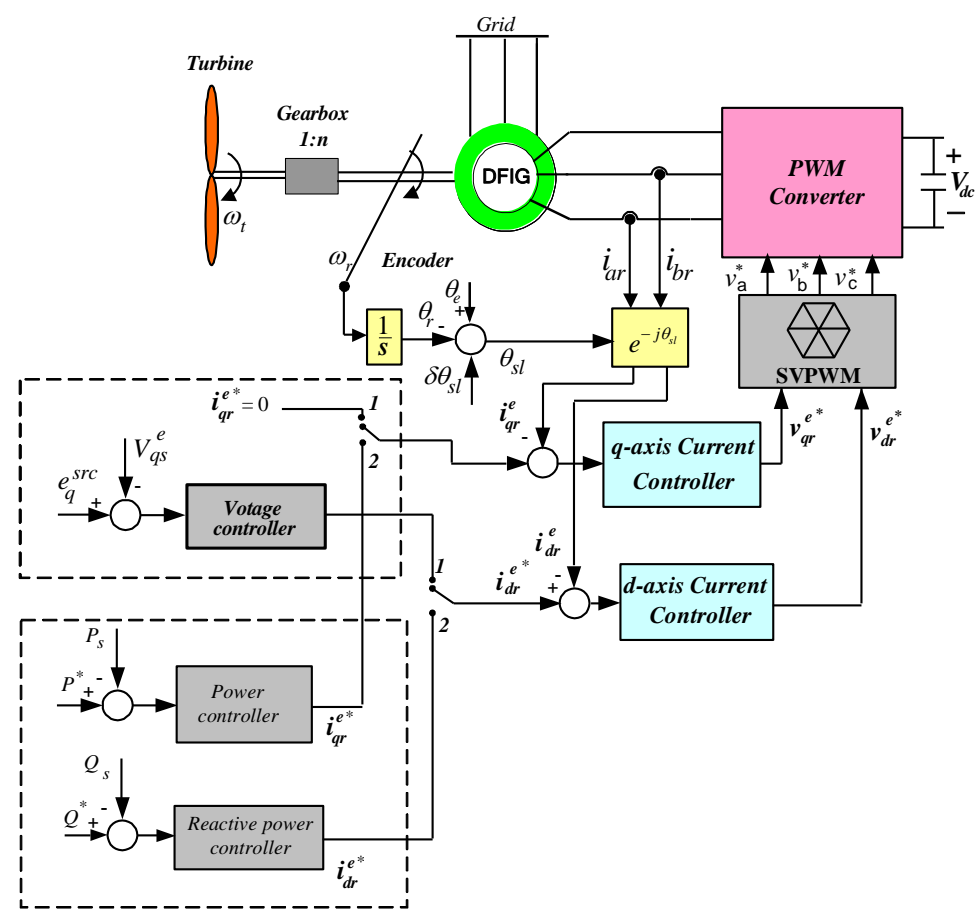

Fig. 10. Control block diagram of the DFIG system.

The DFIG optimum power $P^{*}$ is the reference power value determined by the wind speed and rotor angular speed of the power controller loop. A simple proportional-integral (PI) controller can be utilized to regulate the $\mathrm{d}$-q component of the rotor current only if the reference frames for both the measured and reference current vectors match [51], [52]. 


\section{Experimental Results}

In order to validate the methods presented in this work, a wind turbine emulator was implemented on an experimental bench. The induction motor is controlled in order to reproduce the same dynamics and behavior in the generator axis in a steady state as a wind turbine. The configuration and description of the system were performed in section 3. Fig. 10 shows the motor-generator group used in this work. The experimental bench consists of two 3-kW three-phase induction machines coupled by the shaft.

(a)

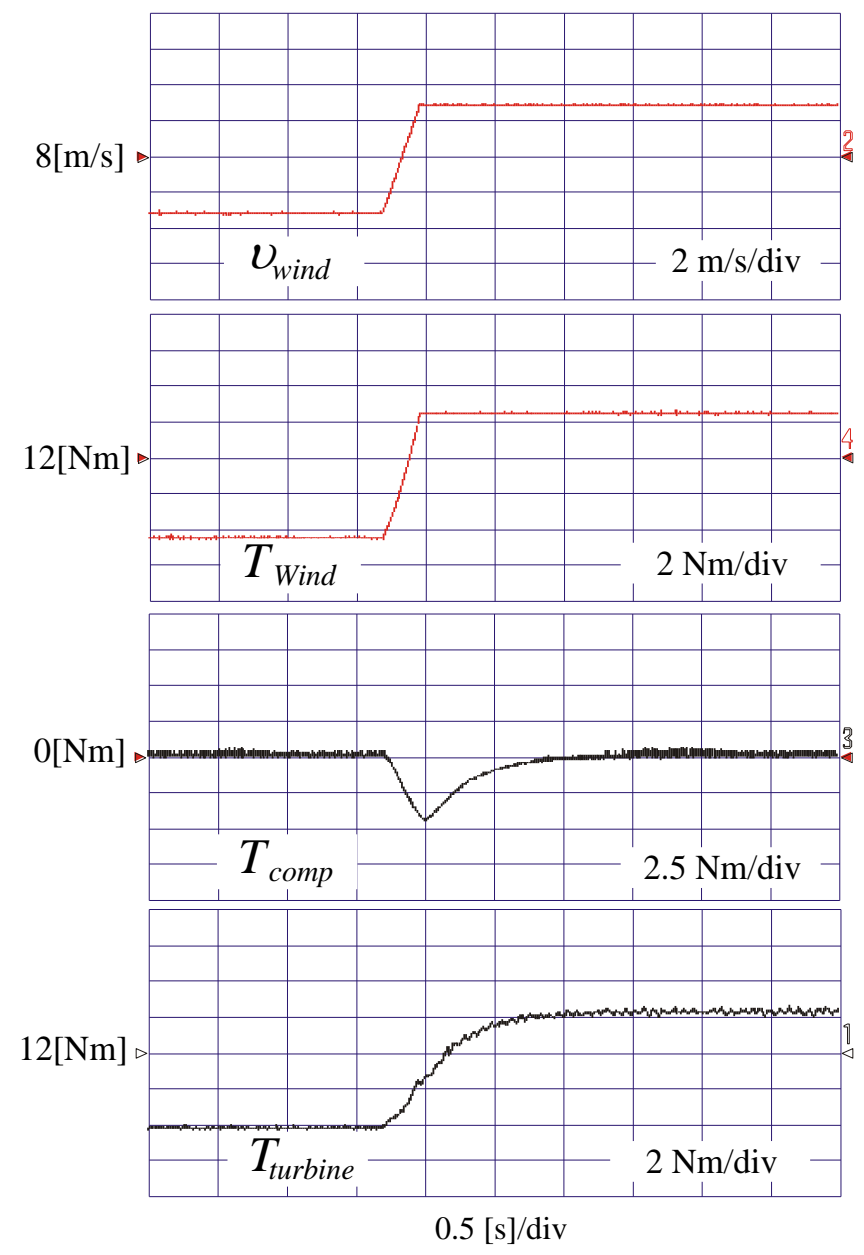

Fig. 11. Blade inertia effect. (a) Wind speed, (b) Wind torque, (c) Compensation torque, (d) Turbine total torque.

For small wind turbine, the turbine torque changes quickly as the wind speed change. To consider the real effect of speed change on a high inertia turbine, a compensation torque component is calculated and added to the turbine torque. The compensation torque can be positive or negative depend on the decreasing or increasing wind speed. Figs. 11 (a) and (b) show the wind speed variation and the corresponding wind torque; respectively. It can be observed that the torque follows the wind speed changes. To consider the slow torque change of high inertia wind turbine, the compensation torque shown in Fig. 11(c) is calculated and then added to the wind torque. Fig. 11(d) shows the total torque of high inertia wind turbine. 
(a)

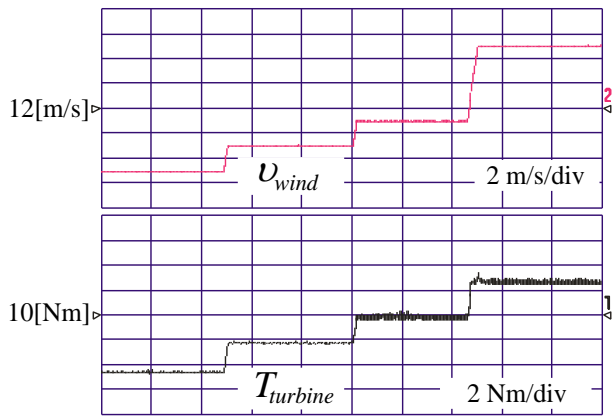

(b)

(c)

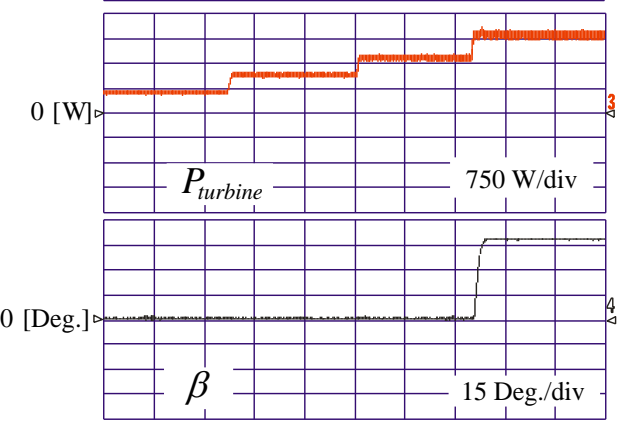

$0.5[\mathrm{~s}] / \mathrm{div}$

Fig. 12. Step variation of wind speed (a) Wind speed [m/s] , (b) Turbine torque [Nm], (c) Turbine power [kW] (d) and Pitch angle[deg.].

To evaluate the performance of the pitch-controlled wind turbine system, a set of step response simulations with deterministic wind speed without turbulences are performed, of which results are shown in Fig. 12. At wind speed lower than $13[\mathrm{~m} / \mathrm{s}]$, the pitch angle controller is deactivated, keeping the pitch angle constant to the minimum value. The turbine power and speed are continuously increased as the wind speed increases. At wind speed higher than $13[\mathrm{~m} / \mathrm{s}]$, the pitch angle controller is activated and limits the output power to the rated value.

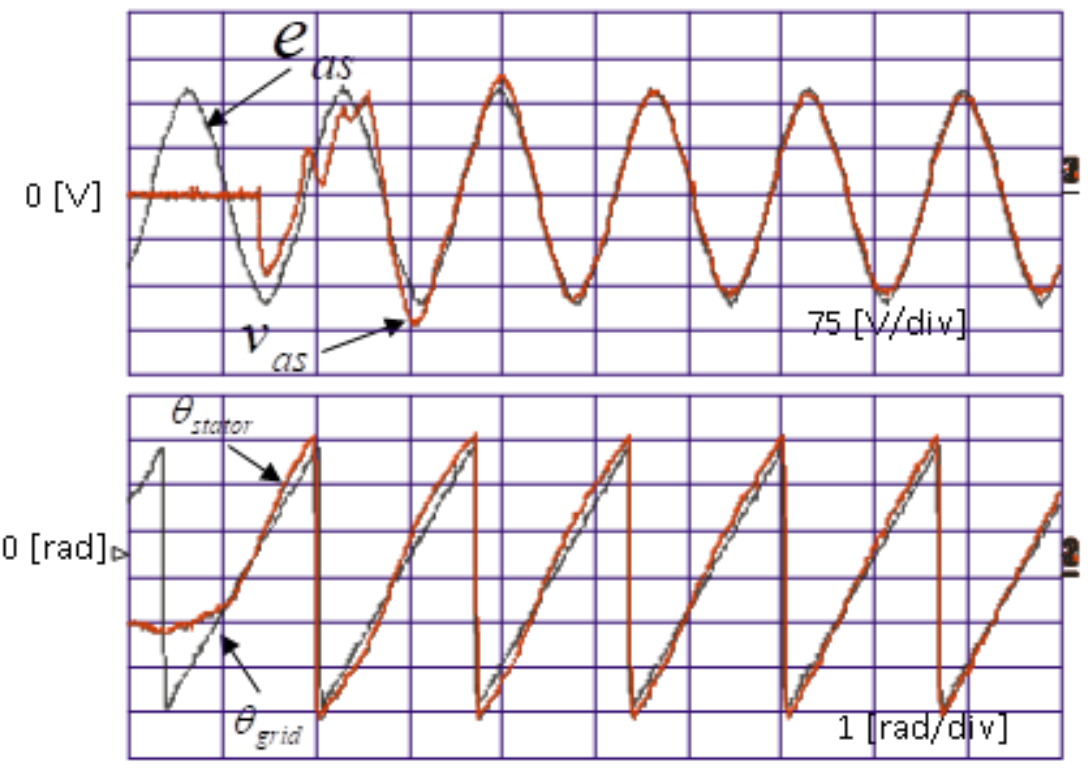

$10[\mathrm{~ms} / \mathrm{div}]$

Fig. 13. Synchronization stator and grid. (a) Phase angle, (b) Voltage. 
The synchronization process is depicted in Fig. 13, where the stator voltage is synchronized with the grid one. From zero stator voltage, the rotor d-axis current is controlled in order to build up the stator voltage in a short time. Meanwhile, the phase shift between the two voltages is compensated using the proposed PLL algorithm. The synchronization process takes place in an almost couple cycles as shown in the Fig. 13. It is well known that the back-to-back PWM converters provide a bidirectional power-flow control thereby enabling the DFIG to operate either in sub synchronous or in super synchronous modes.

(a)

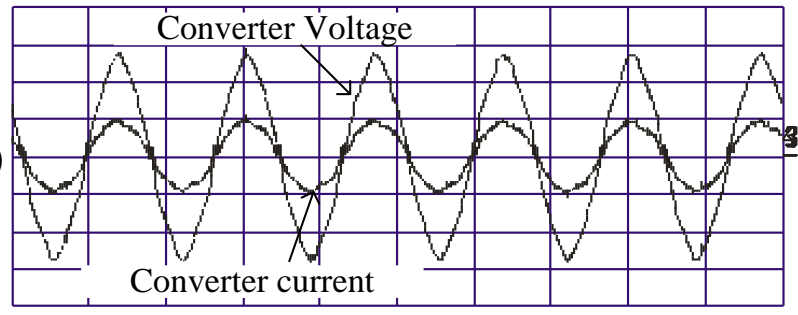

(b)

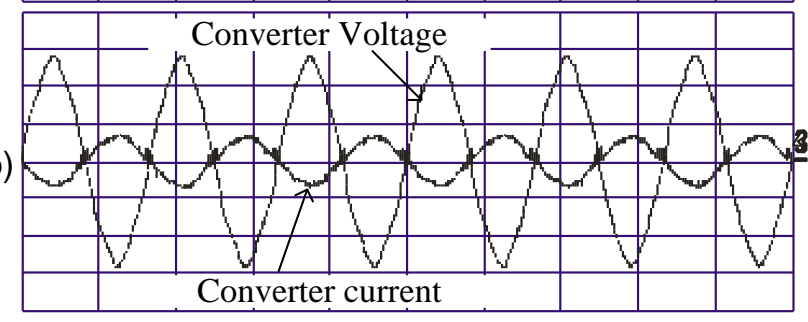

$10[\mathrm{~ms}] / \mathrm{div}$

Fig. 14. Voltage and current of grid-side converter in super synchronous and sub-synchronous speed.

Fig. 14(a) shows that the converter input current flows in phase with the converter input voltage in the sub synchronous mode which means the current is supplied by the grid to the rotor. If the generator speed increases to the super synchronous, the phase shift changes to 180 which means the current is supplied by rotor to the grid as shown in Fig. 14(b).

\section{Conclusion}

In this paper, the main proposal was the emulation of a wind turbine in an experimental bench, and for that, we used an induction motor squirrel cage driven by a back-to-back converter. This simulator aims to reproduce the same behavior as a wind turbine, that is, the generator must operate as if it were connected to a real turbine. In this line, a wind profile implemented by using a computer program and its output is used as an input signal. This signal together with the speed measured on the axis serves as the input variable of the emulated turbine. Thus, it was possible to calculate the turbine's aerodynamic torque. Remembering that, in the simulation of the turbine with speed control, the electric torque of reference was used, thus, the dynamic equation of the speed was solved inside the computer. As observed in the simulation and experimental results, the objective of controlling was achieved. In accordance with the aforementioned, the advantage of this model is the possibility of simulating different turbines with different inertia constants and different wind profiles. This simulation presents a simpler implementation, since it is possible to simulate several turbines with their respective moments of inertia without the need to install flywheels on the axis of the generator motor group, for each case to be simulated.

Still in this work, it was proposed to start the engine by a torque signal, that is, the engine is started so that it generates the same torque on the generator shaft as a wind turbine. The generator was directly connected to the electrical network. The motor provides torque variations proportional to the speed variations of the simulation wind, thus, measurements of the energy generated by the generator and its dynamic behavior, to the variations of the torques were made. on the bench, the pitch angle control proved to be an efficient method to limit the power extracted by the turbine, in situations of speeds above the rated speed. 


\section{References}

[1] A. G. Abo-Khalil, "Impacts of wind farms on power system stability," in Wind Farm, ISBN 980-953-307-562-9, 2013.

[2] A. G. Abo-Khalil and D. C. Lee, "Grid connection of doubly-fed induction generators in wind Energy conversion system," Power Electronics and Motion Control Conf. Proc., 2006, 2, 1-5.

[3] F. Martinez, L. C. Herrero, and S. D. Pablo, "Open-loop wind turbine emulator," Renew. Energ., 2014, 63, 212-221.

[4] M. Arifujjaman," Emulation of a small wind turbine system with a separately-excited dc machine. IU-Journal of Electrical \& Electronics Engineering, 8(1), 2012, 569-579.

[5] Ahmed G. Abo-Khalil, Ali M Eltamaly, P. R. Praveen, Ali S. Alghamdi, I. Tlili, "A Sensorless Wind Speed and Rotor Position Control of PMSG in Wind Power Generation Systems", Sustainability 12 (20), 8481, October, 2020.

[6] Ahmed G. Abo-Khalil, "Control system of DFIG for Wind Power Generation Systems," LAP LAMBERT Academic Publishing, ISBN-10: 3659649813, ISBN-13: 978-3659649813, 2015.

[7] F.-J. Lin, L.-T. Teng, P.-H., Hieh, Y.-F. Li," Intelligent controlled-wind-turbine emulator and induction-generator system using RBFN," IEE Proceeding on Electric Power Applications, 2006.

[8] L. Yang, S. Yan, Z. Chen, W. Liu," A novel wind turbine simulator for wind energy conversion systems using an permanent magnet synchronous motor," International Conference on Electrical Machines and Systems (ICEMS), 2013.

[9] D. Dolan and P. Lehn, "Simulation model of wind turbine 3p torque oscillations due to wind shear and tower shadow," IEEE Transactions on Energy Conversion, 2006, 21(3), pp. 717-724.

[10] H. M. Kojabadi, L. Chang, and T. Boutot, "Development of a novel wind turbine simulator for wind energy conversion systems using an inverter-controlled induction motor," IEEE T. Energy. Conver., 2004, 19, 547-552.

[11] A. Sokolovs, L. Grigans, E. Kamolins, J. Voitkans, “ An Induction Motor Based Wind Turbine Emulator," Latvian Journal of Physics and Technical Sciences, 51(2), 2014, 11-21.

[12] A. G. Abo-Khalil and D. C. Lee, "MPPT control of wind generation systems based on estimated wind speed using SVR," IEEE Transactions on Industrial Electronics, 2008, 55(3), 1489-1490.

[13] A. G. Abo-Khalil, H. G. Kim, D. C. Lee, and J. K. Seok, "Maximum output power control of wind generation system considering loss minimization of machines," IEEE IECON Conf. Proc., 2004, 1676-1681.

[14] L. Mihet-Popa, F. Blaabjerg, and I. Boldea, "Wind turbine generator modeling and simulation where rotational speed is the controlled variable," IEEE T. Ind. Appl., 2004, 40, 3-10.

[15] Ahmed G. Abo-Khalil and Hammad Ab-Zied, "Sensorless Control for DFIG Wind Turbines Based on Support Vector Regression," Industrial Electronics Conference IECON, Canada, Oct. 2012.

[16] A. Sajadi, Ł. Rosłaniec, and M. Kłos, "An emulator for fixed pitch wind turbine studies.” Renew. Energ., 2016, 87, 391 402.

[17] F. M. Hughes, O. Anaya-Lara, and G. Ramtharan, "Influence of tower shadow and wind turbulence on the performance of power system stabilizers for DFIG-based wind farms," IEEE T. Energy. Conver., 2008, 23, 519-528.

[18] A. M. Eltamaly, M. S. Al-Saud, Khairy Sayed, Ahmed G. Abo-Khalil," Sensorless Active and Reactive Control for DFIG Wind Turbines Using Opposition-Based Learning Technique", Sustainability 12 (9), 3583, April 2020.

[19] J. Tan, W. Hu, X. Wang, "Effect of tower shadow and wind shear in a wind farm on AC tie-line power oscillations of interconnected power systems," Energies, 2013, 6, 6352-6372.

[20] A. G. Abo-Khalil and H. Abo-Zied, "Sensorless control for dfig wind turbine based on support vector regression," in IECON 2012 38th Annual Conference on IEEE Industrial Electronics Society, IEEE, 2012, 3475-3480.

[21] A. G. Abo-Khalil and D. C. Lee, "MPPT control of wind generation systems based on estimated wind speed using SVR," IEEE Transactions on Industrial Electronics, 2008, 55(3), 1489-1490.

[22] A. G. Abo-Khalil, "Model-based optimal efficiency control of induction generators for wind power systems," IEEE International Conference on Industrial Technology (ICIT), 2011, 191-197.

[23] A. G. Abo-Khalil, "Synchronization of DFIG output voltage to utility grid in wind power system," Elsevier Journal of Renewable Energy, 2012, 44, pp. 193-198.

[24] J. F. Manwell, J. G. McGowan, and A. L. Rogers, Wind Energy Explained: Theory, Design and Application, Wiley, 2010.

[25] A. G. Abo-Khalil, D.C. Lee," SVR-based wind speed estimation for power control of wind energy generation system," In Proceeding of Power Conversion Conference; IEEE, Nagoya, Japan, 2007, pp. 1431-1436.

[26] Ahmed G. Abo-Khalil, Saeed Alyami, Khairy Sayed, Ayman Alhejji,” Dynamic Modeling of Wind Turbines Based on Estimated Wind Speed under Turbulent Conditions,” Energies, 12(10), PP. 1907, 2109.

[27] I. M. Gregory, R. S. Chowdhry, J. D. McMinn, and J. D. Shaughnessy, "Hypersonic vehicle model and control law development using $H_{\infty}$ and $\mu$ synthesis," NASA Technical Memorandum 4562, Oct. 1994.

[28] A. G. Abo-Khalil, H. G. Kim, D. C. Lee, and J. K. Seok, "Maximum output power control of wind generation system considering loss minimization of machines," IEEE IECON Conf. Proc., 2004, 1676-1681.

[29] S. N. Vukosavic and E. Levi, "Robust DSP-based efficiency optimization of a variable speed induction motor drive," IEEE Trans. Ind. Electron., 2003, 50(3), 560-570.

[30] Ahmed G. Abo-Khalil and D. C. Lee, "Maximum power point tracking based on sensorless wind speed using support vector regression," IEEE Transactions on Industrial Electronics, Vol. 55, No. 3, March 2008. 
[31] K. R. Cho, J. K. Seok, and D. C. Lee, "Mechanical parameter identification of servo systems using robust support vector regression,” IEEE PESC Conf. Proc., 2004, 5, 3425-3430.

[32] H. G. Park, A. G. Abo-Khalil, D. C. Lee, and K. M. Son, "Torque ripple elimination for doubly fed induction motors under unbalanced source voltage," Proc. Power Electronics and Drive Systems (PEDS), 2007, 7, 1301-1306.

[33] A. G. Abo-Khalil, H. G. Park, and D. C. Lee, "Loss minimization control for doubly fed induction generators in variable speed wind turbines,” Proc. IECON '07, 2007, 1109-1114.

[34] Ahmed G. Abo-Khalil, A. Alghamdi, I. Tlili, A, Eltamaly, “A. Current Controller Design for DFIG-based Wind Turbines Using State Feedback Control,” IET Renewable Power Generation, 13 (11), pp. 1938-1949, 2019.

[35] Ahmed G. Abo-Khalil, A. S. Alghamdi, A. M. Eltamaly, M. S. Al-Saud, P. R. Praveen, K. Sayed," Design of State Feedback Current Controller for Fast Synchronization of DFIG in Wind Power Generation Systems," Energies 12 (12), pp. $2427,2019$.

[36] A. M. Eltamaly, M. S. Al-Saud, Ahmed G. Abo-Khalil,” Dynamic Control of a DFIG Wind Power Generation System to Mitigate Unbalanced Grid Voltage," IEEE Access, February 2020.

[37] A. G. Abo-Khalil and D-C Lee, "Grid connection of doubly-fed induction generators in wind Energy conversion system," Power Electronics and Motion Control Conf. Proc., vol. 2, pp. 1-5, 2006.

[38] A. G. Abokhalil," Grid Connection Control of DFIG for Variable Speed Wind Turbines under Turbulent Conditions," International Journal of Renewable Energy Research (IJRER) 9 (3), pp. 1260-1271, 2019.

[39] H. K. Kim, Ahmed Abo-Khalil, D. C. Lee, and J. K. Seok, " Grid-Connected Wind Power Generation System Using Cage-Type Induction Generators," Proc. of Korean Institute of Power Electronics Conf., pp. 73-76, 2003.

[40] Ahmed G. Abo-Khalil and D. C. Lee "Synchronization of Wind power Generation System using DFIG to Utility Grid", Proc. of Korean Institute of Power Electronics Conf., pp. 91-95, Nov. 2005.

[41] Ahmed G. Abo-Khalil and D. C. Lee "Optimal Efficiency Control of Wind Generation System Using Fuzzy Logic Control," Proc. Korean Institute of Electrical Engineering Conf., July 2005.

[42] Ahmed Abo-Khalil and D. C. Lee, "Wind Turbine Simulator Including Pitch Angle Control, Shaft Torsional Vibration and Tower Effect ", Proc. Korean Institute of Electrical Engineering Conf., pp. 411-413, 2005.

[43] Ahmed G. Abo-Khalil and D. C. Lee "Output Power Control of Wind Generation System using Estimated Wind Speed by Support Vector Regression”, Proc. of Korean Institute of Power Electronics Conf., pp. 345-348, June 2006.

[44] Ahmed G. Abo-Khalil and D. C. Lee, "Implementation of Grid-Connection of DFIG for Wind power Generation system," Proc. Korean Institute of Electrical Engineering Conf. Oct. 2006.

[45] Ahmed G. Abo-Khalil, D. C. Lee, J. K. Seok, " Variable Speed Wind Power Generation System Based on Fuzzy Logic Control for Maximum Output Power Tracking ," Proc. Power Electronics Specialists Conference'04, pp. 2039-2043, 2004.

[46] Ahmed G. Abo-Khalil and D. C. Lee "Loss Minimization Control for Induction Generator in Wind Power Systems using Support Vector Regression”, Proc. of Korean Institute of Power Electronics Conf., pp. 341-344, April 2006.

[47] Ahmed G. Abo-Khalil and D. C. Lee, " Grid Connection of Doubly-Fed Induction Generators in Wind Energy Conversion," Proc. IPEMC, China, August 2006.

[48] Ahmed G. Abo-Khalil, H. G. Kim, D. C. Lee and J. K. Seok, " Maximum Output Power Control of Wind Generation System Considering Loss Minimization of Machines ," Proc. IECON'04, pp. 1676 - 1681, 2004.

[49] Ahmed G. Abo-Khalil and D. C. Lee, "Dynamic Modeling and Control of Wind Turbines for Grid-Connected Wind Generation System," Proc. Power Electronics Specialists Conference, PESC, Korea 2006.

[50] Ahmed G. Abo-Khalil, H.-G. Park and D. C. Lee and "Loss Minimization Control for Doubly-Fed Induction Generators in Variable Speed Wind Turbines," Proc. IECON'07, pp. 1109 - 1114, Nov. 2007.

[51] H. G. Park, Ahmed G. Abo-Khalil, D. C. Lee," Wind turbine simulators considering turbine dynamic characteristics," The Transactions of The Korean Institute of Electrical Engineers 57 (4), pp. 617-624, 2008.

[52] Ahmed G. Abo-Khalil "A New Wind Turbine Simulator using a Squirrel-Cage Motor for Wind Power Generation Systems " The Power Electronics and Drive Systems Conference PEDS, December 2011, Singapore.

\section{Appendix A.}

The specification of the induction machine used for test is three-phase, four poles, $230 \mathrm{~V}, 50 \mathrm{~Hz}, 3 \mathrm{~kW}$.

\begin{tabular}{ll}
\multicolumn{2}{l}{ TABLE 1. PARAMETERS OF TURBINE BLADE MODEL } \\
\hline Parameters & Value \\
\hline Blade radius & $0.95[\mathrm{~m}]$ \\
Max. power conv. coeff. & 0.45 \\
Optimal tip-speed ratio & 7 \\
Cut-in speed & $4[\mathrm{~m} / \mathrm{s}]$ \\
Rated wind speed & $13[\mathrm{~m} / \mathrm{s}]$
\end{tabular}


Abo-Khalil and Sayed: WIND TURBINE SIMULATION AND CONTR

TABLE 2. PARAMETERS OF 3KW SCIG

\begin{tabular}{ll}
\hline Parameters & Value \\
\hline Stator resistance & $0.93[\Omega]$ \\
Rotor resistance & $0.533[\Omega]$ \\
Iron loss resistance & $190[\Omega]$ \\
Stator leakage inductance & $0.003[\mathrm{H}]$ \\
Rotor leakage inductance & $0.003[\mathrm{H}]$ \\
Mutual inductance & $0.076[\mathrm{H}]$
\end{tabular}

